\title{
COTIDIANO E MATERIALIDADE DA ESCOLA PRIMÁRIA OITOCENTISTA: RUÍDOS ENTRE PÚBLICO E PRIVADO
}

\author{
Everyday life and materiality of the nineteenth-century elementary school: noises \\ between public and private
}
Vida cotidiana y materialidad de la escuela elemental del siglo xix: ruidos entre público y privado

Valdeniza Maria Lopes da Barra*

\begin{abstract}
Resumo
Eis aqui a reunião de um conjunto de fatos "miúdos" cujas marcas são pinçadas no curso do século XIX, com vistas a pensar a implementação da escola primária. Embora a ênfase seja sobre a escola de Goiás, de vez em quando, como forma de alicerçar o entendimento, chamar-se-á evidências da escola primária da de São Paulo ou outras pistas, de escala nacional, num movimento que, nos seus limites, cuida da relação entre singularidade e totalidade. Face a este conjunto, o esforço de identificar o que está nas ordens da repetição e do acontecimento. Este último, o acontecimento, segundo Braudel (1995) se acredita "único" e se associa à instantaneidade. Enquanto certos atos ou fatos se repetem e, em acontecendo, tornam-se generalidade ou estrutura. Inscritos no "rés do chão", na "zona opaca" - o cotidiano - a repetição de fatos miúdos guarda em si, a "força da inércia" e se revela na capacidade de invadir diferentes níveis da sociedade, portanto, uma "obreira da história" que não se pode menosprezar. Em síntese, é esta a senha de acesso ao movimento de instituição da especificidade do espaço físico da escola primária no curso do século XIX. ${ }^{1}$
\end{abstract}

PALAVRAS-CHAVE: Escola. Instrução primária. Casa.

\begin{abstract}
Here is the meeting of a set of "kids" facts whose marks are painted in the course of the NINETEENTH century, with a view to thinking the implementation of the elementary school. Although the emphasis is on the school of Goiás, once in a while, as a way of supporting the understanding, it will be called evidence from the primary school of São Paulo or other clues, on a national scale, in a movement that, in its limits, takes care of the relationship between Singularity and totality. Faced with this set, the effort to identify what is in the orders of repetition and the event. The latter, the event, according to Braudel (1995) is believed to be "unique" and is associated with instantaneity. While certain acts or facts are repeated and, in happening, they become generality or structure. Inscribed on the "Ground floor", in the "opaque zone"-the daily routine-the repetition of children's facts guard itself, the "force of inertia" and reveals itself in the ability to invade different

\footnotetext{
* Graduada em Pedagogia pela Fundação do Ensino Superior de Rio Verde (GO). Realizou Mestrado (2001) e Doutorado (2005) em Educação no Programa de Estudos Pós-Graduados em Educação: História, Política, Sociedade pela Pontifícia Universidade Católica de São Paulo. É professora associada da Faculdade de Educação da Universidade Federal de Goiás, com atuação na graduação e no Programa de Pós-Graduação em Educação. Email: dabarra@yahoo.com.br

${ }^{1}$ A versão inicial deste trabalho foi apresentada, por ocasião do IV Encontro de história da educação do Centro Oeste - EHECO, realizado em novembro de 2017, na Universidade Estadual do Mato Grosso do Sul. O mesmo integrava o conjunto dos trabalhos da mesa redonda intitulada Instituições escolares e sua materialidade: o público e o privado em questão, sob a coordenação da Profa. Dra. Eurize Pessanha.
} 
levels of society, therefore, a "story-maker" that cannot be underestimated. In summary, this is the password of access to the movement of institution of the specificity of the physical space of the primary school in the course of the NINETEENTH century.

KEYWORDS: School. Primary education. House.

\begin{abstract}
Resumen
Aquí está la reunión de un conjunto de "niños" hechos cuyas marcas se pellizcan en el curso del siglo XIX, con el fin de pensar en la aplicación de la escuela elemental. Mientras que el énfasis está en la escuela de Goiás, de vez en cuando, como una manera de construir en el entendimiento, se llamará evidencia de la escuela elemental de Sao Paulo u otros carriles de base nacional, en un movimiento que, en sus límites, se encarga de la relación entre Singularidad y totalidad. Frente a este conjunto, el esfuerzo por identificar lo que está en las órdenes de repetición y el acontecimiento. Este último, el acontecimiento, según Braudel (1995) se cree para ser "único" y se asocia a inmediatez. Mientras que ciertos actos o hechos se repiten y, al suceder, se convierten en generales o estructura. Inscrita en la planta baja, en la "zona opaca"-la vida cotidiana-la repetición de los hechos los niños se guardan, la "fuerza de la inercia" y se revela en la capacidad de invadir diferentes niveles de la sociedad, por lo tanto, un "obreros de la historia" que uno no puede despreciar. En Resumen, esta es la contraseña de acceso al movimiento de institución de la especificidad del espacio físico de la escuela primaria en el curso del siglo XIX.
\end{abstract}

PALABRAS CLAVE: Escuela. Instrucción primaria. Casa.

\title{
INTRODUÇÃO
}

\section{Escola: inventatio abstraída materialidade}

O período seguinte à primeira lei de instrução brasileira, Carta de Lei sobre as Escolas de Primeiras Letras, de 15 de outubro de 1827 em conjunto com o Ato Adicional de 1834 desencadearão, no plano das províncias, diferentes dispositivos de normatização da instrução pública elementar. Em Goiás, isto acontecerá com a Lei n. 13 de 23 de julho de 1835. Já no texto da lei maior, identifica-se que a escola brasileira do império se institui como um projeto de vocação civilizatória para o qual se define o método de ensino (mútuo), o currículo (leitura, escrita, matemática, moral cristã), enquanto a sua efetivação se dará nas localidades "em que for possível estabelecerem-se". (art. $4^{\circ}$.) A possibilidade de se estabelecer, uma escola, ou não, tem relação direta com a estrutura física existente em cada localidade. Para as escolas [...] se applicarão os edifficios que houverem" (art. $5^{\circ}$.). Compete ao poder público dispor da estrutura física que tiver, como forma de solucionar a demanda de espaço físico que possa sediar o serviço público a ser desenvolvido pela escola. Distingue-se na letra da lei, o tratamento conferido à provisão do espaço físico da escola: "os utensílios necessários à custa da Fazenda Publica" (art. 5.). As motivações parecem ser aquelas, de natureza econômica, sendo muito mais econômica a aquisição de utensílios do que a construção de prédios. Notase que a equação dada pela ausência de prédio e oferta de utensílios, como se destacou na lei nacional de instrução pública (1827), se reproduzirá no cotidiano das províncias. Mas este processo, tal como ensina Braudel (1995), é eivado pela inércia que atua como "obreira da história".

A anterioridade da escola - projeto - sobre o espaço físico, talvez corresponda ao que pode ser compreendido como a inventatio da escola. Entre inventar e efetivar a escola, há que se produzir a sua "receptividade", a sua "necessidade", admitindo-se de empréstimo, palavras de Braudel. (1995, p. 305). Impõe-se compreender o movimento marcado pela inventatio e a usurpatio. Acredita-se que, tanto a receptividade como a necessidade da escola são 
construções históricas. A questão é, de que modo, o espaço físico, o mobiliário, os utensílios; seus cruzamentos podem se constituir como caminho para compreender a produção da escola primária.

A primeira lei goiana (n. 13, 23 de julho de 1835), em matéria de instrução primaria, cuida da graduação da escola, das matérias de ensino, da frequência de alunos, dos processos de admissão de professores, inspeção, dentre outros. Entretanto, destaca-se que, no texto de vinte e seis artigos, há um único registro sobre o local de funcionamento de escola. "Os pais de famílias saó obrigados á dar a seos filhos a instrucção primaria do primeiro graó, ou nas Escolas Publicas, ou particulares, ou em suas próprias casas" (art.9 ${ }^{\circ}$.). Diante do qual, entende-se que a família, embora tenha a obrigação de garantir a instrução primária dos filhos, não é obrigada a levá-los para a escola pública, podendo oferecer essa instrução "em suas próprias casas". Não há, nesta lei, entretanto, qualquer pista material acerca do local de funcionamento da escola pública. Isto é, a escola sobre a qual se regulamenta até a condição para quem a ela se recusa, parece ser abstraída da materialidade. Algumas décadas mais tarde, alguns textos normativos da instrução goiana instruirão acerca da escola pública, seu espaço de funcionamento e sua provisão material.

Quadro 1 - Materiais de leitura e escrita, aluguel de casa/escola e mobiliário

\begin{tabular}{|l|l|l|}
\hline \multicolumn{1}{|c|}{ Documento } & \multicolumn{1}{|c|}{ Descrição } & \multicolumn{1}{|c|}{$\begin{array}{c}\text { Objeto de } \\
\text { instrução }\end{array}$} \\
\hline $\begin{array}{l}\text { Regulamento } \\
\text { de } 1856, \text { art. } \\
100\end{array}$ & $\begin{array}{l}\text { "o professor receberia quantia rasoavel para papel e penas, } \\
\text { tintas, lápis, e Compêndios para os meninos pobres". }\end{array}$ & Utensílios/materiais \\
\hline $\begin{array}{l}\text { Lei n. } 11, \text { de } \\
09 / 11 / 1857\end{array}$ & $\begin{array}{l}\text { Se prevê a destinação de verbas para o aluguel de casas para as } \\
\text { escolas de Primeiras Letras. }\end{array}$ & $\begin{array}{l}\text { Espaço/Local de } \\
\text { funcionamento da } \\
\text { escola }\end{array}$ \\
\hline $\begin{array}{l}\text { Regulamento } \\
\text { de } 1869\end{array}$ & $\begin{array}{l}\text { "todo o expediente assim como a mobilia da aula serão } \\
\text { fornecidos pelos cofres provinciaes." }\end{array}$ & Mobiliário \\
\hline
\end{tabular}

Fontes: Regulamento de 1856, Lei n. 11, de 09/11/1857, Regulamento de 1869.

O Regulamento de 1856 define "o methodo que deve ser seguido nas escolas", s razões que podem justificar o fechamento de "qualquer escola", condições para remoção de professores de "d'uma para outra escola", tipifica aqueles que "não podem freqüentar as escolas" e, como se vê no quadro acima, estabelece o modus operandi pelo qual se disporá de utensílios de escrita e material de leitura aos "meninos pobres" da escola. No ano seguinte (1857), a lei informa a previsão de orçamento para o aluguel de "casas" para o funcionamento de escolas e, em pouco mais de uma década (1869), se terá a preocupação com a oferta de mobiliário para as escolas goianas. Vê-se assim, que há, em Goiás, desde o texto de 1835 uma aparente hierarquia, de ordem material, construída na relação entre inventatio e a usurpatio da escola. Nesta hierarquia vislumbra-se a escola como o constructo permanente a justificar, em primeiro lugar, a demanda por materiais de escrita e leitura, seguida pelo local de funcionamento e, em terceiro lugar, o mobiliário. Nesta ordem. E esta não é uma ordem de somenos importância, pois nela é possível aventar rumores da receptividade e necessidade da escola junto ao seio social, assim como das contingências materiais daquele contexto.

\section{Casa: o espaço de funcionamento da escola pública}


Com o Regulamento de 1869 e a respectiva instrução acerca do aluguel de casas para o funcionamento da escola, emergirão diferentes situações advindas do par: casa $x$ escola. "A casa onde funcionar a escola, que também servirá para a vivenda do professor, será alugada, logo que seja possível e a província não possua prédio próprio, por conta dos cofres provinciais" (Art. 36, Reg. 1869). Notar-se-á que o dispositivo legal que faculta ao professor a dupla experiência de vida na casa-escola, isto é, possibilidade tanto de "vivenda" como exercício do magistério, também corrobora a deflagração de um conjunto de questões que, no plano cotidiano, são reveladores da tensão entre público e privado. A implementação das ações supostas pelo exercício da instrução, ou os ensaios de usurpatio, vão promover a eclosão de problemas que podem ser reunidos em dois grupos. No primeiro as dificuldades de acomodar o espaço físico da casa alugada à dupla função: morar e ensinar. No segundo grupo estariam as questões de ordem ética e moral aspiradas pelo exercício do magistério e tensionadas pela condição da casa.

Ora, é importante considerar qual é o limite desta que pode ser tomada como uma novidade, ou seja, a casa como sede espacial da função de moradia e trabalho. Braudel (1995) ensina que até o século XVIII inexistia divisão entre habitação e trabalho. É também este autor, para quem "uma casa seja ela qual for, dura e não pára de testemunhar a lentidão das civilizações" (1995, p.238). E então, faz sentido consultar o Dicionário de Língua Brasileira, autoria de Luiz Maria da Silva Pinto, cuja primeira edição é de 1832, este define casa da seguinte maneira:

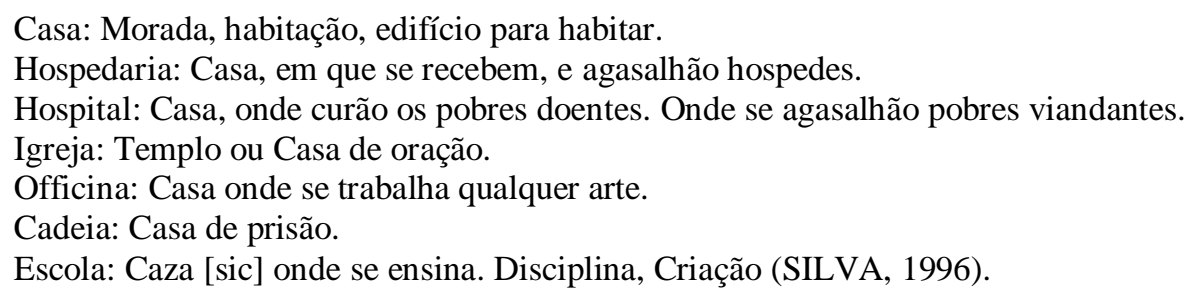

Enquanto o dicionarista dos oitocentos define a função de habitação a partir da palavra casa, há na sequência, uma inversão da casa pelas funções nela desenvolvidas. Em outras palavras, as diferentes funções, que não a de habitar, subvertem o sentido matricial da casa. Assim é que, a palavra casa deixa de ser o verbete sobre o qual se define, deslocando-se para o plano que explica a função. Veja-se: "Escola: Caza onde se ensina."

Em consulta ao Livro de Correspondências da Presidência da Província Goiana aos Funcionários da Instrução Pública Goiana (1847-1861), Nancy Silva, encontrou o registro que orientava sobre os critérios para "a casa ideal para escola" (SILVA, 1975, 121):

(...) informe se o repartimento e systema de engradamento do edificio permitte que
reuna as ditas salas o espaço ocupado pelas respectivas alcovas, quaes dimensões
destas, bem como se são assoalhadas e forradas as salas, alcovas e varanda. Outro
sim se he possivel dividir-se a varanda em outros dous quartos suficientemente
claros e arejados com communicação pa. o salão, e deixando-se entre elles passagem
para o quintal (Livro de Correspondências da Presidência da Província aos
Funcionários da Instrução Publica, Goiás 1847-1861 apud SILVA, 1975, nota 36, p.
121).

Se em Nancy Silva destacam-se os critérios oficiais a guiar a locação da casa, chama a atenção em Genesco Bretas (1991), a sua interpretação acerca da lógica que orientava o professor ao alugar uma casa para escola. 
(...) cada professor instalava sua escola onde e como quisesse, em sua própria morada, quando a possuía, ou em casa por ele próprio alugada. Quando o professor era nomeado e vinha de fora, ao chegar procurava uma casa de aluguel, tendo a preocupação de encontrar uma com as seguintes características: que fosse a mais afastada possível do centro, "na rua de baixo", de preferência (para dificultar a fiscalização do Inspetor Paroquial e os olhares das pessoas mais representativas do lugar); que não tivesse a sala principal muito grande (para não caber muitos alunos); que tivesse um quintal grande (para nele fazer suas plantações de mandioca, milho e feijão, e a criação de galinhas e engorda de um porco, para complementar o necessário para sua subsistência); e cujo aluguel fosse o mais barato possível (BRETAS, 1991, p. 403).

Pairava ainda, no intervalo marcado pela inventatio e usurpatio, aspectos referentes ao asseio e salubridade do espaço no qual abrigava meninos, dia a dia, em nome da instrução.

\begin{abstract}
(...) se instalava a escola, em geral numa casa velha, sem forro (que na época não era usado), sem assoalho, de chão batido. Com o tempo esse chão (piso) não era nada plano ou liso, mas cheio de buracos, feitos sob a ação da vassoura, das unhas das galinhas e dos focinhos de porcos, e servindo de ninhos para gatos, cachorros, porcos e pulgas, com os quais os meninos tinham de conviver, infestando-se ainda, não só de piolhos, mas também de bichos de pé (BRETAS, 1991, 403-404).
\end{abstract}

Os três fragmentos acima são amostras de como o cotidiano pode conter uma dialética esclarecedora da coexistência de cúpula e base. Neste sentido, faz sentido lembrar Azanha (1990), quando afirma que "é no interior da sala de aula" que se avalia a eficácia ou o destino de uma política. Se esta assertiva procede, não são casuais, algumas medidas dos governos goiano e brasileiro acerca do espaço físico de funcionamento da escola primária.

O relatório de presidencial de 1875, informava que Antero de Assis, presidente da província de Goiás, teria encomendado ao engenheiro da província goiana, uma planta para edifício escolar, cuja cópia teria sido enviada às câmaras municipais. (Rel. pres., 1875. Rev. Memórias Goianas n.12, p. 19). O mesmo presidente, estabeleceu, por meio da Resolução n. $517,07 / 07 / 1874$ que nenhuma povoação seria elevada de freguesia à categoria de vila ou cidade sem ter um edifício público para escolas de primeiras letras do sexo masculino. Tratam-se os dois atos de medidas locais que têm correspondência com as discussões de plano nacional.

Na década de 1870, os diagnósticos dos mais diferentes profissionais (...) eram unânimes em afirmar o estado de precariedade dos espaços ocupados pelas escolas, sobretudo públicas, mas não somente essas, e advogavam a urgência de se construírem espaços específicos para a realização da escola primária (FARIA FILHO e VIDAL, 2001, p. 23; FARIA FILHO e VIDAL, 2005, p. 49).

Não se conseguiu acessar tais plantas, mas pode-se afirmar que, em Goiás, das 84 escolas criadas em 1875, seis funcionavam em casas adquiridas pelo governo provincial, sendo as demais cedidas por particulares ou alugadas. Tais doações permitiam ao Presidente da Província, Cícero de Assis, informar que, no ano de 1876, havia em Goiás, nove escolas 
públicas que funcionavam em prédios próprios. (Rel. pres. 1876). A tentativa de identificar mais detalhes acerca de tais números resultou no quadro 2.

Quadro 2 -Casas para escola: iniciativa pública e privada

\begin{tabular}{|l|l|l|}
\hline Localidade & Ano & Inciativas pública e privada \\
\hline Cidade de Goyaz & 1874 & Governo da província compra casa para a escola de Corumbá \\
\hline Bonfim & 1874 & Coronel Francisco Silva constrói casa para escola feminina \\
\hline Flores & & Coronel Firmino Oliveira doa prédio próximo da matriz \\
\hline Bela Vista & & Antonio Canedo doa casa para escola \\
\hline Santa Rosa & & Cícero Gomes doa casa para escola \\
\hline
\end{tabular}

Fontes: BARRA, Valdeniza Maria Lopes da. O lugar da escola primária goiana entre os séculos XIX e XX. In: CASTRO \& CASTELLANOS (org.). A escola e seus artefato culturais. São Luis: EDUFMA, 2013.

Apesar da intenção oficial manifestada na demanda por uma planta arquitetônica para a escola, a produção do espaço específico para o funcionamento da escola pública primária que fosse apartado da função doméstica, constitui, no último quartil do século XIX, uma iniciativa rala, de traço predominante da iniciativa privada, como informam os dados do quadro 2. A grande maioria das escolas funcionarão em casas alugadas, como se pode ver no quadro 3, os valores trimestrais repassados ao professor da escola localizada em São José do Tocantins.

Quadro 3 - Exemplo de controle de verbas destinada ao pagamento de aluguel de casa

\begin{tabular}{|l|l|l|l|}
\hline $\begin{array}{l}\text { Expediente } \begin{array}{l}\text { Período de referência/ } \\
\text { Liberação }\end{array} \\
\text { Jul. a set. de } 1871\end{array}$ & $\begin{array}{l}\text { Aluguel } \\
\text { Período de referência/ } \\
\text { Liberação }\end{array}$ \\
\hline Out. a dez de 1871 & 3.000 rs & Jul. a set. de 1871 & 6.000 rs \\
\hline Jan. a Jun. de 1872 & 3.000 rs & Out. a dez de 1871 & 6.000 rs \\
\hline Total & 6.000 rs & Jan. a Jun. de 1872 & 12.000 rs \\
\hline
\end{tabular}

Fonte: Folha de pagamento de aluguéis e expediente das aulas de instrução primária da província. Documentação vinculada à Tesouraria da Fazenda Provincial, sob responsabilidade de João Baptista Carneiro. Série: Relação da documentação manuscrita, datilografada e impressa. Referência n. 0521 AHE-GO.

A indivisão entre habitação e instrução torna, tanto a ação de alugar casa para escola, como a condição de casa locada para escola, a base que sediará episódios diversos, cujo cerne é a tensão inscrita na fronteira entre público e privado. Exemplo disso, são os acontecimentos ocorridos na província paulista.

\section{Quadro 4 - Casas/escolas paulistas: alguns episódios}

\begin{tabular}{|l|l|l|}
\hline Ano & Local & Síntese do episódio/processos administrativos e disciplinares \\
\hline 1889 & Cotia & Professora processada: atraso nos trabalhos na escola, dada a dificuldade de alugar casa. \\
\hline 1881 & Bananal & Professora processada: maus costumes do marido em casa (escola). \\
\hline 1887 & Cunha & Professor é acusado de morar na casa (escola) com amásia \\
\hline 1887 & Socorro & Professor rouba relógio de escola (casa) para comprar relógio de bolso. \\
\hline
\end{tabular}

Fonte: BARRA, Valdeniza M. L. da. Briga de vizinhos: um estudo dos processos de constituição da escola pública de instrução primária na província paulista (1853-1889). TD. São Paulo: PUC, 2005. 
Na tese de doutorado intitulada Briga de vizinhos: um estudo dos processos de constituição da escola pública de instrução primaria paulista (1853-1889), advoga-se o entendimento de que, aspectos advindos da tensão inscrita no espaço doméstico com função do exercício público do magistério, também teria contribuído na explicitação da demanda da especificidade de um espaço específico para a função escolar. (BARRA, 2005, p. 252).

Admite-se, portanto que, os conflitos advindos da indivisão entre habitação e instrução favoreceriam "aspectos constituintes da escola chamada moderna", já que, ao se instalarem no cotidiano da escola, também forçavam a interlocução entre cúpula governo) e base (cotidiano escolar). Nessa direção, também se trata de considerar que "a produção de uma forma escolar" envolveu "situações que exprimiam os limites entre o tempo do professor o tempo do homem que exercia a função de professor" (2005, p. 252).

O relógio da escola de Socorro (SP), tal como se vê na linha 4 do quadro 4, teria sido furtado pelo professor, desencadeando-se assim, um processo disciplinar. O relógio evidencia que certos utensílios proviam a escola pública, primária, paulista. Se havia estratégias da inspetoria paulista para tratar da subtração do relógio da escola, também havia controle na oferta de utensílios para as escolas, em qualquer que fosse a província. A Tesouraria da Fazenda Provincial de Goiás concentrava, numa de suas sessões, as questões atinentes às despesas gerais, dentre as quais, a instrução. "Nada era adquirido ou fornecido sem prévia anuência", enquanto "relações e pedidos passavam pelo julgamento do Chefe". (SILVA, 1875, nota 61, p. 133).

Pedidos, eram então, reduzidos à metade ou simplesmente indeferidos. Advertências eram feitas à Inspetoria acerca dos professores descuidados com o material de sua aula. O pagamento para transporte de material era fixado no justo preço. Para pedidos de objetos já solicitados, lembravam-se: "no último pedido deu-se-lhe canivete e agora torna a exigir outro" (SILVA, 1975, nota 61, p. 133).

O controle do expediente aberto pelos cofres públicos se pronunciava nas diferentes etapas da provisão material da escola, revelando, inclusive, o cuidado com a duração dos objetos, como demonstra o fragmento relativo ao canivete: "pedidos de objetos já solicitados, lembravam-se: "no último pedido deu-se-lhe canivete e agora torna a exigir outro". Ou ainda, como se vê a seguir, na última coluna do quadro de distribuição de utensílios às escolas goianas, a sugestão de duração anual dos respectivos materiais, a relação entre quantidade de materiais por escola, por alunos, etc.

Quadro 5 - Distribuição de utensílios às escolas goianas (1859)

\begin{tabular}{|c|c|c|c|c|c|c|c|c|}
\hline Papel almasso & \multicolumn{4}{|c|}{ Para cada dos meninos } & 1 & Penna para & 1 & Anno \\
\hline Pennas d'ave & II & II & II & II & 120 & II & II & II \\
\hline Lapis & II & II & II & II & 20 & II & II & II \\
\hline Canivetes & II & II & II & II & 2 & II & II & II \\
\hline Reguas & II & II & II & II & 3 & II & 3 & II \\
\hline Tinta & II & II & II & II & 2 & Garrafas II & 1 & II \\
\hline Tinteiros & II & II & II & II & 6 & II & 2 & II \\
\hline Collecção de traslados & II & II & II & II & 1 & II & II & II \\
\hline Lousas & II & II & $\mathrm{II}$ & II & 5 & II & 3 & II \\
\hline Canetas de metal & II & II & II & II & 5 & II & II & II \\
\hline Lapis de pedra & II & II & II & II & 40 & II & 1 & II \\
\hline
\end{tabular}




\begin{tabular}{|c|c|c|c|c|c|c|c|c|}
\hline Gis & II & II & II & II & 1 & Libra & II & II \\
\hline Esponja & II & II & II & II & 4 & Onça II & II & II \\
\hline Cartas de A.B.C e Syllabas & II & II & II & II & 5 & II & II & II \\
\hline Catechismos históricos & II & II & II & II & 5 & II & II & II \\
\hline $\begin{array}{l}\text { Compendios de Doutrina ou } \\
\text { Cartilha }\end{array}$ & II & II & II & II & 6 & II & II & II \\
\hline Historia do Brazil & II & II & II & II & 5 & II & 2 & II \\
\hline Grammaticas & II & II & II & II & 2 & II & 1 & II \\
\hline Compendios de Arithmetica & II & II & II & II & 6 & Il & II & II \\
\hline $\begin{array}{l}\text { Sciencias do Bom } \\
\text { Ricardo }\end{array}$ & II & II & II & II & 6 & Il & II & II \\
\hline Geographias da Mocidade & \multicolumn{4}{|c|}{ Para cada escola } & 1 & & & \\
\hline Mappas do Brasil & II & II & II & II & 1 & & & \\
\hline $\begin{array}{l}\text { Manual encyclopedico de Monte- } \\
\text { Verde }\end{array}$ & II & II & II & II & 1 & & & \\
\hline
\end{tabular}

Fonte: VALDEZ, Diane. Livros para o expediente das aulas primárias na Província de Goiás (1850-1890). In: BARRA, V. M. L. da. Estudos de história da educação de Goiás (1830-1930). Goiânia: Editora da PUC-GO, 2011. p. $115-130$.

A tematização do percurso histórico do espaço físico da escola vai revelando nuanças de sua constituição. Entre as quais, se destaca, na provisão material, a anterioridade de utensílios sobre o mobiliário. Ao mesmo tempo, se constata a prevalência dos utensílios que suportam as ações de escrever e ler. E, ainda, no quesito utensílios, a invariância dos mesmos. Desta base empírica, dois aspectos constituintes da escola primária emergem. Um deles é a vocação em difundir leitura e escrita e o outro aspecto, somente compreensível na equação analítica que incorpora a condição de inquilinato da escola primária oitocentista. Quer isto dizer que, a anterioridade dos utensílios de ler e escrever, sobre o mobiliário de provisão da escola oitocentista, tem relação com a condição nômade imposta pelo inquilinato, isto é, pela ausência de um ponto fixo.

Esta hipótese interpretativa é endossada pelo procedimento que cruza dados sobre duração prevista de mobiliário e a duração, em média, do contrato de locação de uma casa. Enquanto um móvel escolar deveria durar de 15 a 20 anos (Diretoria de Rendas Provinciais, 1863-1873), o prazo de um contrato de aluguel de casa de escola era de 3 anos. (Regulamento de 1869). Esse descompasso alimenta a compreensão de que o investimento em bens de maior durabilidade era inibido pela ausência de um espaço específico para o exercício da escola, cuja condição era a de inquilina. A cada três anos - prazo do contrato de aluguel - poderia ser necessário mudar a escola de "casa", Não por acaso, Braudel dirá que "a mais frágil das habitações é a tenda dos nômades”. (1995, p. 245). Numa habitação de nômade, diz Braudel, não há mesas, não há cadeiras, "nem quadros".

Mas a ocorrência do mobiliário na casa alugada para escola se impõe. A usurpatio aqui encarnada nos gestos exigidos pelo corpo para os exercícios que prometem o domínio da escrita e da leitura demandam suportes materiais afins. Tais suportes incluem cadeiras (bancos, mochos) e mesas. "O mais importante é a posição sentada que mesa e tamborete implicam, uma maneira de viver" (Braudel, 1995, p. 258). O mesmo Braudel dirá que a procura das "origens deste comportamento" - vida sentada - seja o trono do soberano, o assento do mandarim, ou "bancos e cadeiras da escola" - poderia nos levar às raízes da civilização ocidental. (1995, p. 261). É possível que um episódio narrado por Barra (2016), possa ser correspondente daquilo que Braudel (1995) aludiu como a tirania do espaço enfrentada pelo móvel. 
A localidade em questão é a Vila de Capivari (SP), o período vai de 1852 a 1854 . A Comissão de Móveis e Utensílios, órgão da Inspetoria de Geral de Instrução Paulista, envia para as escolas a informação de que cada escola receberá: a) para o professor: 1 mesa de 5 palmos, e cadeira sobre o estrado; para os alunos: 10 mochos para meninas, 2 mesas de 8 palmos de comprimento e 4 de largura, 2 bancos de 20 palmos. Diante das especificações, responde a professora Profa. Innocencia Querubina (Escola Feminina de Capivari, 28 de março de 1852): "A sala de Aula e em casa de minha rezidencia alugada a 55\$rs. Annuaes, e tem 25 palmos de frente com 20 de fundo, expansão esta, que não é suficiente pa. bem acomodar as discípulas (...)". A mesma professora solicita mobiliário que se ajuste às dimensões do cômodo de sua casa, alugado para a função de escola: 4 bancos de 12 palmos, 2 mesas de 6 palmos de comprimento e 4 de largura, 1 mesa de 5 palmos em quadra e 1 cadeira sobre o estrado, 6 mochos para as meninas escreverem.

Por sua vez, na província goiana, a presença de mobiliário na escola foi identificada para fins deste estudo - a partir dos anos 60 do século XIX. Seria, a partir daí, que, mobiliário e utensílios compartilhariam a cena da provisão material da escola.

\section{Quadro 6 - Provisão material da escola primária goiana na segunda metade do século} XIX

\begin{tabular}{|c|c|c|}
\hline $\begin{array}{l}x \\
\bar{x} \\
0 \\
0 \\
0 \\
0\end{array}$ & $\begin{array}{l}\text { Canetas, papel, penas, lápis, compêndios, } \\
\text { cartas de alfabeto, sílabas, nomes e } \\
\text { conselhos morais, tinta, compêndios de } \\
\text { aritmética, compêndios de Doutrina Cristã, } \\
\text { livros de leitura, livros de matrícula, artes } \\
\text { portuguesas, traslados, canetas, lápis de } \\
\text { lousas, lousas, cartas }(a, b, c) \text { e tinteiros. }\end{array}$ & Mesa com 4 gavetas e tamboretes. \\
\hline 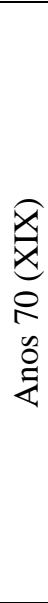 & $\begin{array}{l}\text { Livros de matrícula, livro de visita, } \\
\text { catecismos, tinteiros, canetas, cartas de } \\
\text { leitura, coleções de Doutrina Christã, } \\
\text { taboadas, Regulamento das Aulas, papel, } \\
\text { botijas de tinta, cartilhas, pedras, lousas } \\
\text { para contas, réguas, folhinha de parede, } \\
\text { penas de aço e tinta, lápis,", livros de } \\
\text { leitura, folhetos de normas de cartas, } \\
\text { Compêndio de história, Manual do } \\
\text { Professor Primário, traslados, silabários de } \\
\text { letras redondas, cartas }(a, b, c) \text {. } \\
\text { Pote de água, vassouras. }\end{array}$ & $\begin{array}{l}1 \text { mesa grande, } 2 \text { bancos e } 2 \text { tamboretes; conserto de } \\
2 \text { bancos e aquisição de } 1 \text { banco; fechaduras para } \\
\text { gavetas de mesas; } 4 \text { bancos com } 4 \mathrm{~m} \text { de } \\
\text { comprimento, } 1 \text { mesa com } 3 \mathrm{~m} \text { comprimento, } 2 \\
\text { bancos com } 12 \text { palmos; pede } 8 \text { bancos, } 2 \text { mesas e } \\
\text { informa ter } 2 \text { mesas, } 1 \text { banco de } 8 \mathrm{~m} \text { de comprimento, } \\
1 \text { taboa; pedido de } 3 \text { bancos grandes, uma mesa } \\
\text { grande e } 1 \text { mesa pequena; pedido de } 1 \text { mesa grande } \\
\text { para alunos, } 1 \text { mesa menor para professor; pedido de } \\
2 \text { bancos grandes, } 4 \text { cadeiras encouradas; } 1 \text { mesa } \\
\text { grande com } 10 \text { palmos de comprimento e } 5 \text { de } \\
\text { largura, } 2 \text { bancos de } 14 \text { palmos cada e } 6 \text { de largura, } 2 \\
\text { bancos de } 12 \text { palmos com } 5 \text { de largura, } 1 \text { armário } \\
\text { com } 10 \text { palmos por } 18 \text {; solicita conserto de mesa } \\
\text { grande. }\end{array}$ \\
\hline $\begin{array}{l}x \\
\bar{x} \\
0 \\
\infty \\
0 \\
0 \\
0\end{array}$ & $\begin{array}{l}\text { Tinteiro e areeiro de chumbo, livros, } \\
\text { lousas, baeta, papel, penas, lousa, penas, } \\
\text { lousa, methodo de leitura e escripta de } \\
\text { Agostinho Penido, objetos e Regulamento e } \\
\text { Instrução Pública, Coleção de Leis da } \\
\text { Provincia. } \\
\text { Potes para água, copos e pratos; botija de } \\
\text { barro; } 1 \text { copo de folha e um prato de folha. }\end{array}$ & $\begin{array}{l}\text { Mesa, cadeira, tamboretes; mesas, bancos; } 1 \text { mesa de } \\
1 \text { metro de comprimento sobre } 25 \text { centimetros de } \\
\text { largura para o professor devendo ser com gaveta e } \\
\text { chave; } 1 \text { escrivaninha para a mesa do professor, } 1 \\
\text { cadeira, } 2 \text { tamboretes; mesa, cadeira, tamboretes; } 1 \\
\text { mesa com gaveta, } 4 \text { bancos, } 1 \text { cadeira (ou um } \\
\text { tamborete). }\end{array}$ \\
\hline
\end{tabular}

\footnotetext{
${ }^{2}$ Em 1884 foram liberados créditos para a compra de materiais de expediente para a escola situada em Curralinho. Tais materiais provavelmente seriam adquiridos no comércio local: "Depósito J. Almeida".
} 


\begin{tabular}{|c|c|c|}
\hline 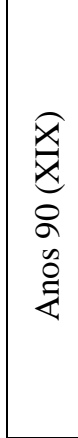 & $\begin{array}{l}\text { Bíblia, canivetes, cartilhas, papel, lápis, } \\
\text { tinta, réguas, traslados, cartas (a, b, c), paus } \\
\text { de giz, dicionários portáteis, alfabeto } \\
\text { parietal, tinteiros, lápis, tinta, pedras, } \\
\text { traslados, cartilhas, lousa, livros, } \\
\text { catecismos, lápis, tesoura, canetas, } \\
\text { cadernos, taboadas, livros de leitura, livros } \\
\text { de ponto, gramáticas, gesso, silabários. } \\
1 \text { relógio de parede; cabides para chapéu; } 1 \\
\text { campainha, } 1 \text { ampulheta; copos; botijas de } \\
\text { barro; vassouras. }\end{array}$ & $\begin{array}{l}\text { Bancos; } 1 \text { banco de } 3 \mathrm{~m} \text {; quadro sobre cavaletes; } \\
\text { quadro preto de aritmética, cadeira forrada e carteira } \\
\text { com cadeira forrada e carteira com gaveta para o } \\
\text { professor; } 1 \text { banco de } 3 \mathrm{~m} \text { de comprimento } 1 \text { tábua } \\
\text { envernizada para contas; recibo de } 44 \text { mil reis por } 3 \\
\text { bancos e uma mesa. }\end{array}$ \\
\hline
\end{tabular}

Fontes: Listas de solicitação e liberação de verbas para aquisição de materiais do expediente escolar e mobiliário. Documentação Manuscrita. AHE-GO. ${ }^{3}$

É possível identificar no quadro acima, que, na segunda metade do século XIX, houve uma trajetória a revelar que, saiu-se da invariância de utensílios de escrita e leitura, para variações interessantes da provisão material da escola. No que concerne aos utensílios, notase o aparecimento de artefatos de medição do tempo (campainha, ampulheta, relógio); artefatos reveladores de urbanidade (cabides para chapéu); artefatos ligados ao consumo de bebida e comida (pratos, copos, potes); artefatos associados à limpeza da escola (vassouras); e novidades nos suportes de leitura (alfabeto parietal).

Em relação ao mobiliário observa-se a incorporação de móveis associados ao assento (cadeira, mesa, mesa com gaveta, banco, tamborete, carteira). Por fim, o destaque para a "taboa", com denominações múltiplas (quadro sobre cavaletes, quadro preto de aritmética, tábua envernizada para contas). ${ }^{4}$

O último documento normativo da instrução pública, na província goiana, no período imperial, assim instruía sobre o espaço de funcionamento da escola:

\begin{abstract}
As escolas funccionaráo em casas alugadas pelos respectivos professores, excepto aquellas estabelecidas em localidades onde ha prédios pertencentes á provincia. (art. 60, Regulamento 1887). O valor aluguel da casa escola continuaria sendo parte do vencimento do professor, assim como despesas com o asseio da escola e o fornecimento de água. (arts. 61 e 62, Regulamento de 1887). O primeiro documento normativo da instrução pública, no estado goiano, em período republicano, assim instruía sobre o espaço de funcionamento da escola: Abonar-se-á aos professores (...) para aluguel de casa, 40\$ annuaes aos de escola elementar, 60\$ aos de primeira entrância, $120 \$$ aos de $2^{\mathrm{a}} 240 \$$ aos de $3^{\mathrm{a}}$, correndo também por conta do Estado a despesa com expediente e mobília (REGULAMENTO, 1893, art. 46).
\end{abstract}

Em 1918, noventa e um anos após a primeira lei de instrução pública do país, setenta e três anos depois da primeira lei goiana de instrução pública, a Lei do Ensino Primário, no estado goiano, da República Federativa do Brasil, instruía sobre o espaço de funcionamento da escola: "emquanto não for adoptado ou construído um predio para o grupo escola da

\footnotetext{
${ }^{3}$ As listas foram coletadas no Arquivo Histórico Estadual de Goiás por Diane Valdez, quando da realização da pesquisa que resultou no artigo Livros para o expediente das aulas primárias na província de goiás (18501890), in BARRA, V. M. L. da. (org.). Estudos de história da Educação de Goiás (1830-1930). Goiânia: Editora da PUC/GO, p. 2011.Tais listas, entre outros documentos, foram publicadas no DVD Coleção Documentos de História da Educação de Goiás, vol. 1, organizado por Valdeniza Maria Lopes da Barra, lançado em 2012.

${ }^{4}$ A esse respeito indica-se a leitura do livro: Da pedra ao pó: o itinerário da lousa na escola pública paulista do século XIX, autoria de Valdeniza Maria Lopes da Barra. Goiânia: Cegraf/UFG: 2016.
} 
Capital, o Governo poderá installal-o no edifício que offerecer maiores vantagens" (Lei n. 631, 1918).

\section{CONSIDERAÇÕES FINAIS}

A escola oitocentista é um acontecimento que surge no texto legal como entidade definida nos âmbitos do currículo, do método, de critérios de admissão profissional, dentre outros, mas, abstraída do espaço físico. Esta característica de sua nascença marca a trajetória na qual o nomadismo, extensão que deriva do inquilinato - status daquele que não possui território próprio. É esta a condição que explica a repetição e relativa invariância de utensílios de ler e escrever, assim como sua primazia em relação ao mobiliário. Em suma, hierarquia escalonada que estabelece a primazia dos materiais associados aos processos de escrever e ler, sobre o mobiliário que suporta os gestos demandados pelos atos de escrever e ler, revelam que, à precariedade do espaço físico destinado à escola pública primária, sempre se associou o esforço de concretização do seu desideratum. Outrossim, a implantação da escola de tempo integral na rede estadual de Goiás, acontecimento de relevo do início do século XXI, podia ser sintetizado na manchete de um jornal local: "Nossa escola de tempo integral não é feita de prédios, mas de pessoas". (Secretária de Estado da Educação de Goiás, Jornal Opção, Goiânia, 11 a 17/02/2007, p. 18). A desconsideração do espaço físico em face do acontecimento dado pela ampliação da jornada escolar no início do século XIX, constitui amostra de que a série repetitiva de evidências que confrontam a carência do espaço físico escolar, se confunde com a condição de estrutura sedimentada pela "força da inércia" a obrar a história da educação pública.

\section{REFERÊNCIAS}

AZANHA, José Mário Pires. Cultura escolar brasileira: um programa de pesquisas. Revista USP, n. 65. São Paulo: USP, 1990-1991. Disponível em: file:///D:/Usuários/Valdeniza/Desktop/AZANHA_1990.pdf, acesso 05/11/2017.

BARRA, Valdeniza Maria da Barra. Briga de vizinhos: um estudo dos processos de constituição da escola pública de instrução primária na Província Paulista (1853-1889). TD. São Paulo: PUC, 2005.

BARRA, Valdeniza Maria da Barra. O lugar da escola primária goiana entre os séculos XIX e XX. In: CASTRO, Cesar Augusto e CASTELLANOS, Samuel L. V. (Org.). A escola e seus artefatos culturais. São Luis: EDUFMA, 2013, p. 107-140.

BARRA, Valdeniza Maria da Barra. Da pedra ao pó: o itinerário da lousa na escola pública paulista do século XIX. Goiânia: Cegraf/UFG, 2016. 
BRETAS, Genesco. História da instrução pública em Goiás. Goiânia: Cegraf/UFG, 1991.

BRAUDEL, Fernand. As estruturas do cotidiano: o possível e o impossível. São Paulo: Martins Fontes, 1995.

FARIA FILHO, L. M. de e VIDAL, D. G. Os tempos e os espaços escolares no processo de institucionalização da escola primária no Brasil. Revista Brasileira de História da Educação. SP/Campinas: Autores Associados, 2000.

FARIA FILHO, L. M. de e VIDAL, D. G. Os tempos e os espaços escolares no processo de institucionalização da escola primária no Brasil. As lentes da história: estudos de história e historiografia da educação no Brasil. São Paulo/Campinas: Autores Associados, 2005. p. 4171.

Folha de pagamento de aluguéis e expediente das aulas de instrução primária da província. Tesouraria da Fazenda Provincial, sob responsabilidade de João Baptista Carneiro. Série: Relação da documentação manuscrita, datilografada e impressa. Referência n. 0521 AHE-GO.

LEI n. 631 do Ensino Primário, Goiás, 1918. AHE-GO.

PINTO, Luiz M. da S. Diccionario da Lingua Brasileira. Goiânia: Sociedade Goiana de Cultura/Instituto de Pesquisas e Estudos Históricos do Brasil Central: Centro de Cultura Goiana, 1996. Edição facsimilada publicada em 1832.

Primeira Lei Goiana sobre Instrucção Primaria, 1835. Bretas, 1991.

Regulamento sobre a Instrucção Primaria, 1856. Biblioteca Nacional do Rio de Janeiro.

Regulamento da Instrução Pública e Particular da Província de Goias, 1869. AHE-GO.

Regulamento para a Instrucção Primaria da Provincia de Goyaz, 1887. AHE-GO.

Regulamento da Instrucção Primaria, Goiás, 1900. AHE-GO.

SILVA, Nancy Ribeiro de Araújo e. Tradição e inovação educacional em Goiás. Goiânia: Oriente, 1975. 
VALDEZ, Diane. Livros para o expediente das aulas primárias na Província de Goiás (18501890). In: BARRA, V. M. L. da. Estudos de história da educação de Goiás (1830-1930). Goiânia: Editora da PUC-GO, 2011. p. 115-130.

Recebido em: 10 de março/2018

Aceito em:19 de julho/ 2018 